\title{
Serum Homocysteine and Folate Levels in Korean Schizophrenic Patients
}

\author{
Tae Ho Kim and Seok Woo Moon \\ Department of Psychiatry, Research Institute of Medical Science, Konkuk University School of Medicine, Chungju, Korea
}

\begin{abstract}
Objective This study was conducted to confirm the results of the authors' previous research on schizophrenia manifesting high serum homocysteine and low folate levels. This study is anchored on a theory that a high serum homocysteine concentration affects schizophrenia by virtue of a neurotoxic mechanism, and on a report that some schizophrenia patients with high homocysteine levels benefited from high folate ingestion.

Methods The serum homocysteine, folate, and vitamin $\mathrm{B}_{12}$ levels of 236 normal-control-group subjects and 234 schizophrenia subjects who met the diagnostic criteria based on DSM-IV-TR were compared. The homocysteine levels were measured via fluorescence polarization immunoassay, and the folate and vitamin $\mathrm{B}_{12}$ levels were determined via radioimmunoassay.

Results The homocysteine levels of the patient group were significantly higher than those of the normal control group. The homocysteine level was more negatively correlated with the folate level in the schizophrenia group than in the control group. The percentages of female and male schizophrenia subjects manifesting high homocysteine levels were 33.8 and $51.5 \%$, respectively. The percentage of schizophrenia subjects with low folate levels was $66.2 \%$. In the low- and normal-folate-level groups, the patient group showed significantly higher homocysteine levels than the normal control group. The low-folate-level patient group particularly showed significantly higher homocysteine levels than the low-folate-level normal control group.
\end{abstract}

Conclusion Some schizophrenia patients with high serum homocysteine levels may have the genetic defect of having low folate serum levels. In such cases, folate ingestion may be a good management modality for clinical improvement.

Psychiatry Investig 2011;8:134-140

Key Words Schizophrenia, Homocysteine, Folate.

\section{INTRODUCTION}

Extensive studies have revealed that increased serum homocysteine is a risk factor of cardiovascular diseases such as myocardial infarction, carotid stenosis, cerebral hemorrhage, and vascular dementia; of neuropsychiatric diseases, including the neural-tube defect; of degenerative diseases such as Alzheimer's disease, mild cognitive impairment, and Parkinson's disease; and of depressive disorder and schizophrenia. ${ }^{1-7}$ For the pathological mechanism of the cardiovascular system, homocysteine is known to hamper vasodilation by hindering deoxyribonucleic acid (DNA) synthesis in the vascular endo-

Received: April 9, 2010 Revised: November 25, 2010

Accepted: December 17, 2010 Available online: January 20, 2011

$\triangle$ Correspondence: Seok Woo Moon, MD, PhD

Department of Psychiatry, Konkuk University School of Medicine, 620-5 Gyohyeon2-dong, Chungju 380-704, Korea

Tel: +82-43-840-8990, Fax: +82-43-840-8529, E-mail: hessem@kku.ac.kr

(a) This is an Open Access article distributed under the terms of the Creative Commons Attribution Non-Commercial License (http://creativecommons.org/licenses/by$\mathrm{nc} / 3.0$ ) which permits unrestricted non-commercial use, distribution, and reproduction in any medium, provided the original work is properly cited. thelial cell. It is also known to disturb anticoagulation, ${ }^{8}$ but its pathological mechanism for the central nervous system remains unclear. For the brain nerve cells, it has been asserted that DNA damage inflicted by homocysteine induces apoptosis and hypersensitivity to excitotoxicity. ${ }^{9}$ Other studies asserted that homocysteine acts as an excitotoxin on a glycine coagonist site and on a glutamate site in the N-methyl-D-aspartate (NMDA) receptors. ${ }^{10}$

With the growing interest in increased homocysteine, it was found that the major cause of the aforementioned diseases is a defect in the 5,10-methyleneterahydrofolate reductase (MTHFR), which remethylates homocysteine into methionine. Many studies reported that the administration of folate can treat the genetic defect of MTHFR. ${ }^{11-13}$

Regland et al. ${ }^{13}$ showed that in a 27 -year-old female patient with schizophrenia but who showed an improvement in her symptoms after taking the MTHFR catalyzer cobalamine, the cause of her metabolic disorder of increased homocysteine was that her low 5-methyl-terahydrofolate activity led to a reduction in methyleneterahydrofolate, which in turn led to the 
non-remethylation of methyleneterahydrofolate into methionine. Therefore, it is considered that the genetic defect of MTHFR is the primary cause of increased serum homocysteine. ${ }^{14-16}$ The secondary causes are low serum folate and cobalamine levels, which further increase homocysteine.

In Korea, there has yet to be a study on homocysteine and on the genetic variation of MTHFR in schizophrenia patients. In this context, this study was conducted for the following reasons on schizophrenia patients and on normal people who visited the authors' hospital for physical examination: 1) to determine if there is a difference between the serum homocysteine, folate, and vitamin $\mathrm{B}_{12}$ levels of the schizophrenia patients and those of the normal control group; 2) to identify which variables affect the level of homocysteine in both the schizophrenia patients and the normal control group; and 3) to determine if there is any difference in the clinical variables between the patients with increased serum homocysteine and those with low serum homocysteine levels. If meaningful data can be obtained from this study, folate can be administered to schizophrenia patients with abnormal homocysteine metabolism, as a recommended treatment.

\section{METHODS}

\section{Study subjects}

\section{Patient group}

Patients who met the diagnostic criteria of schizophrenia based on DSM-IV-TR ${ }^{17}$ and who did not have a history of any other physical, mental, or genetic disease were included in this study. All the schizophrenia patients were in a non-acute phase of the illness. They were treated with antipsychotic drugs, but none of them took any vitamin supplement three months before their inclusion in this study. There were 234 subject patients in all, each of whom submitted a written informed consent after being fully informed of the purpose and procedure of this study.

\section{Normal control}

Among the people who underwent physical examination for employment, 234 who had no history of physical, mental, or genetic disease were included in the study. They also did not take any vitamin supplement three months before their inclusion in this study. Given that among many circumstantial factors, excluding age and sex, smoking and coffee drinking have been known to increase serum homocysteine the most, ${ }^{18}$ the normal subjects were matched based on their sex, age, smoking status, and coffee intake, using 1 : 1 matching. For smoking and coffee drinking, five cigarettes or more and three cups of coffee or more per day were chosen as the criteria.

\section{Methods}

Measurement of serum homocysteine, folate, and vitamin $\mathrm{B}_{12}$

$10 \mathrm{~mL}$ blood samples were taken from the subjects' antecubital veins before breakfast and were placed in ice-cooled ethylenediaminetetraacetic acid tubes. The samples were kept on ice for 2 hours, and the plasma and blood cells were separated via centrifugation. The plasma samples were stored at $-70^{\circ} \mathrm{C}$ until the homocysteine levels were measured via polarization immunoassay.

The amount of homocysteine was determined via radioimmunoassay (IMx, Abbott, USA) while the amounts of folate and vitamin $B_{12}$ were determined via radioimmunoassay (Cobra II, Packard, USA).

\section{Classification of the clinical variables of the schizophrenia patients}

Two psychiatrists assessed and classified the clinical courses, prognoses, and subtypes of schizophrenia of all the subject patients based on their age of onset, family history of schizophrenia, positive/negative symptoms, presence of auditory hallucination, recovery period, and number of days of hospitalization, after reviewing the medical chart and interviewing the patients.

\section{Statistical analysis}

The demographic differences between the patient and control groups were analyzed using chi-square tests. The plasma concentrations of homocysteine, folate, and vitamin $\mathrm{B}_{12}$ of the patient and control groups, and the differences in homocysteine concentration between the low- and high-folate-level groups, were measured via t-tests. The age of onset of schizophrenia of the high- and low-homocysteine-level groups were compared also via t-tests while the other items were assessed via chi-square tests. The correlation between the variables was studied using Pearson's correlation analysis. Logistic regression analysis was conducted to estimate the schizophrenia risk factor. Statistical analysis was carried out using Statistical Package for the Social Sciences (SPSS) for the Windows 12.0 software (SPSS Inc., Chicago, IL, USA).

\section{RESULTS}

\section{Characteristics of the patient and normal control groups}

The average ages of the patient group $(\mathrm{n}=234)$ and normal control group $(n=234)$ were $40.4 \pm 10.5($ mean $\pm S D)$ and $39.6 \pm$ 13.6 (mean $\pm S D)$, respectively. The numbers of males $(n=99)$ and females $(n=135)$ were the same in each group. There was 
no significant difference between the patient and normal control groups in terms of the age and number of males and females therein.

\section{Comparison of the homocysteine, folate, and vitamin $B_{12}$ levels of the patient and normal control groups}

The homocysteine levels were significantly higher in the patient group than in the normal control group. In contrast, the folate levels were significantly lower in the patient group than in the normal control group. The vitamin $\mathrm{B}_{12}$ levels were within the normal range in both groups, although they were significantly higher in the patient group than in the normal control group. The reason for the higher vitamin $\mathrm{B}_{12}$ levels in the patient group is that the compound vitamin B was administered to the patients in the two hospitals where such patients were hospitalized (Table 1).

\section{Correlation between homocysteine and folate in the patient and normal control groups}

The coefficient of the inverse correlation between homocysteine and folate was higher in the patient group $(-0.313, \mathrm{p}<$ $0.01)$ than in the normal control group $(-0.276, \mathrm{p}<0.01)$. There was also an inverse correlation between homocysteine and vitamin $B_{12}$ in both groups, although the coefficient of the inverse correlation was slightly different between the groups (Table 2).

\section{Comparison of the homocysteine levels of the low-folate-level patient group and of the normal control group}

In this study, a low serum folate level was defined as 3.8

Table 1. Plasma concentrations of homocysteine, folate, and vita$\min B_{12}$

\begin{tabular}{lccc}
\hline \multicolumn{1}{c}{ Variables } & $\begin{array}{c}\text { Schizophrenia } \\
(\mathrm{N}=234)\end{array}$ & $\begin{array}{c}\text { Control } \\
(\mathrm{N}=234)\end{array}$ & $\mathrm{p}$ \\
& $(\mathrm{Mean} \pm \mathrm{SD})$ & $($ Mean $\pm \mathrm{SD})$ & \\
\hline Homocysteine $(\mu \mathrm{M} / \mathrm{L})^{*}$ & $14.30 \pm 13.10$ & $9.12 \pm 6.36$ & $<0.001$ \\
Folate $(\mathrm{ng} / \mathrm{mL})^{*}$ & $3.78 \pm 2.27$ & $5.70 \pm 3.53$ & $<0.001$ \\
Vitamin $\mathrm{B}_{12}(\mathrm{pg} / \mathrm{mL})^{*}$ & $690.34 \pm 314.41$ & $601.78 \pm 211.20$ & $<0.001$ \\
\hline
\end{tabular}

${ }^{*} \mathrm{p}<0.05$ by independent $\mathrm{t}$-test $\mathrm{ng} / \mathrm{mL}$ or less, according to the criteria presented by Suzzer et al. (The serum folate level was $3.8 \mathrm{ng} / \mathrm{mL}$ or less in the lower one-third of the normal control group). ${ }^{19}$ In the comparison of the serum folate levels of the patient group with low serum folate levels and of the normal control group, the number of subjects with low serum folate levels was remarkably high (115) compared with the normal control group (80), while the patient group showed significantly higher homocysteine levels than the normal control group. In the comparison of the patient group with normal serum folate levels and the normal control group, the serum homocysteine levels were significantly higher in the patient group than in the normal control group (Table 3 ).

\section{Correlation between the homocysteine levels and the clinical features of the schizophrenia patients}

In this study, increased serum homocysteine was defined as $12.46 \mu \mathrm{M} / \mathrm{L}$ according to the criteria presented by Virgos et al. (the serum homocysteine level was $12.46 \mu \mathrm{M} / \mathrm{L}$ in $90 \%$ of the normal control group). ${ }^{20}$ When the patient group was divided into the patient group with high serum homocysteine levels and the patient group with normal serum homocysteine levels using this criterion, $33.8 \%$ of all the patients belonged to the patient group with high serum homocysteine levels. In particular, $51.5 \%$ of the male patients belonged to the patient group with high serum homocysteine levels. For the clinical variables, only sex registered a significant difference between the two groups. In the patient group with normal serum homocysteine levels, there were more women than men, and conversely, in the patient group with high serum homocysteine levels, there were more men than women (Table 4 and 5).

\section{Regression analysis of the risk factor of schizophrenia}

The serum homocysteine, folate, and vitamin $B_{12}$ levels as

Table 2. Correlations among homocysteine, folate, and vitamin $\mathrm{B}_{12}$

\begin{tabular}{lcc}
\hline & $\begin{array}{c}\text { Homocysteine- } \\
\text { folate }\end{array}$ & $\begin{array}{c}\text { Homocysteine- } \\
\text { vitamin } \mathrm{B}_{12}\end{array}$ \\
\hline Schizophrenia group $(\mathrm{N}=234)$ & $-0.313^{*}$ & $-0.285^{*}$ \\
Control group $(\mathrm{N}=236)$ & $-0.276^{*}$ & $-0.283^{*}$ \\
\hline
\end{tabular}

${ }^{*} \mathrm{p}<0.01$ by Pearson's correlation

Table 3. Difference in homocysteine concentration between the low- and normal-folate-level groups

\begin{tabular}{lcc}
\hline \multirow{2}{*}{ Variables } & \multicolumn{2}{c}{ Homocysteine concentration (uM/L) } \\
\cline { 2 - 3 } & Low-folate-level group* & Normal-folate-level group \\
\hline Schizophrenia $(\mathrm{N}=234)$ & $16.88 \pm 15.11^{\dagger}(\mathrm{N}=155)$ & $9.23 \pm 4.72^{\ddagger}(\mathrm{N}=79)$ \\
Control $(\mathrm{N}=234)$ & $12.44 \pm 9.88^{\dagger}(\mathrm{N}=80)$ & $7.58 \pm 2.12^{\ddagger}(\mathrm{N}=154)$ \\
\hline
\end{tabular}

*low folate level: $\leq 3.8 \mathrm{ng} / \mathrm{mL}$, the bottom tertile for the control, ${ }^{\dagger}$ schizophrenia vs. control: $\mathrm{p}=0.004$ via independent $\mathrm{t}$-test, ${ }^{\ddagger} \mathrm{schizophrenia}$ vs. control: $\mathrm{p}=0.004$ via independent $\mathrm{t}$-test 
predictor variables differed significantly between the patient group and the normal control group. In the patient group with increased serum homocysteine, the probability of the inci-

Table 4. Demographic difference between the high- and normalhomocysteine-level schizophrenia groups

\begin{tabular}{|c|c|c|c|}
\hline Variables & $\begin{array}{c}\text { Normal- } \\
\text { homocysteine- } \\
\text { level group (below } \\
12.46 \mu \mathrm{M} / \mathrm{L}) \\
(\mathrm{N}=155)\end{array}$ & $\begin{array}{c}\text { High- } \\
\text { homocysteine- } \\
\text { level group (above } \\
12.46 \mu \mathrm{M} / \mathrm{L}) \\
(\mathrm{N}=79)\end{array}$ & $\mathrm{p}$ \\
\hline Sex* & & & $<0.001$ \\
\hline Male $(\mathrm{N}=99)$ & 48 & 51 & \\
\hline Female $(\mathrm{N}=135)$ & 107 & 28 & \\
\hline \multicolumn{4}{|l|}{ Age (years)* } \\
\hline Below $29(\mathrm{~N}=31)$ & 21 & 10 & 0.808 \\
\hline $30-39(\mathrm{~N}=68)$ & 42 & 26 & \\
\hline $40-49(\mathrm{~N}=86)$ & 60 & 26 & \\
\hline $50-59(\mathrm{~N}=40)$ & 27 & 13 & \\
\hline Above $60(\mathrm{~N}=6)$ & 5 & 4 & \\
\hline Family $\mathrm{Hx}^{*}$ & & & 0.588 \\
\hline Absence $(\mathrm{N}=191)$ & 125 & 66 & \\
\hline Presence $(\mathrm{N}=43)$ & 30 & 13 & \\
\hline Age at onset ${ }^{\dagger}$ & $28 \pm 10.0$ & $27.1 \pm 10.8$ & 0.524 \\
\hline
\end{tabular}

*chi square, ${ }^{\dagger} t$-test were done dence of schizophrenia was 1.609 times higher than that in the patient group with normal serum homocysteine levels. Meanwhile, increased serum folate was found to reduce the probability of the incidence of schizophrenia. These variables, however, were not suitable for use as decisive predictor variables because their odd ratios were not sufficiently large.

\section{DISCUSSION}

Homocysteine, a sulfur amino acid, is an intermediate metabolite that is formed in the course of its conversion from methionine into cysteine. Homocysteine is metabolized via either of two major pathways. In remethylation, homocysteine is converted into methionine by methionine synthase, which uses vitamin $\mathrm{B}_{12}$ as a cofactor. For this conversion, the methyl group is provided by MTHF, which is produced by a reaction catalyzed by MTHFR. Second, it can be metabolized into cysteine via transsulfation. Homocysteine is metabolized into cysteine by cystathionine $\beta$-synthase, a vitamin- $\mathrm{B}_{6}$-dependent enzyme. In the brain, remethylation is the one and only metabolic pathway.

The metabolism of homocysteine is most highly affected by the folate level and also by various environmental factors, such as food, in addition to genetic factors, typically MTHFR. An increase in serum homocysteine is brought about by smok-

Table 5. Clinical difference between the high- and normal-homocysteine-level schizophrenia groups

\begin{tabular}{|c|c|c|c|}
\hline Variables & $\begin{array}{c}\text { Normal-homocysteine-level group } \\
\text { (below } 12.46 \mu \mathrm{M} / \mathrm{L})(\mathrm{N}=155)\end{array}$ & $\begin{array}{l}\text { High-homocysteine-level group } \\
\text { (above } 12.46 \mu \mathrm{M} / \mathrm{L})(\mathrm{N}=79)\end{array}$ & $\mathrm{p}^{*}$ \\
\hline Positive/negative sx. & & & 0.192 \\
\hline Negative $(\mathrm{N}=56)$ & 36 & 20 & \\
\hline Positive $(\mathrm{N}=170)$ & 116 & 54 & \\
\hline Positive/Negative $(\mathrm{N}=6)$ & 2 & 4 & \\
\hline Course & & & 0.165 \\
\hline Acute recovered $(\mathrm{N}=54)$ & 40 & 14 & \\
\hline Chronic deteriorate $(\mathrm{N}=180)$ & 115 & 65 & \\
\hline Prognosis & & & 0.093 \\
\hline Good $(\mathrm{N}=11)$ & 8 & 3 & \\
\hline Moderate $(\mathrm{N}=113)$ & 82 & 31 & \\
\hline $\operatorname{Bad}(\mathrm{N}=1,110)$ & 65 & 45 & \\
\hline Disease subtypes & & & 0.266 \\
\hline Undifferentiated $(\mathrm{N}=77)$ & 83 & 37 & \\
\hline Paranoid $(\mathrm{N}=110)$ & 22 & 11 & \\
\hline Disorganized $(\mathrm{N}=33)$ & 46 & 31 & \\
\hline Residual $(\mathrm{N}=4)$ & 4 & 0 & \\
\hline Auditory hallucination & & & 0.563 \\
\hline Absence $(\mathrm{N}=30)$ & 18 & 12 & \\
\hline Presence $(\mathrm{N}=203)$ & 137 & 66 & \\
\hline
\end{tabular}

High homocysteinemia: $\geq 12.46 \mu \mathrm{M} / \mathrm{L}$, the 90 th percentile for the control group. ${ }^{*} \mathrm{p}$ values calculated via chi-square test 
ing, coffee, age, vitamin $\mathrm{B}_{6}$, vitamin $\mathrm{B}_{2}$, the male gender, alcohol consumption, creatinine, and hypertension. ${ }^{14,18}$ The normal serum homocysteine level is $5-15 \mu \mathrm{M} / \mathrm{L}$, and its level in cerebrospinal fluid and in the brain tissue is known to be $0.5-10$ $\mu \mathrm{M} / \mathrm{L} .{ }^{19}$ At present, the mechanism of neurodegeneration due to increased serum homocysteine remains unclear.

Kruman et al. ${ }^{9}$ observed that homocysteine induced the susceptibility of the hippocampal-nerve cells in a rat to apoptosis and excitotoxicity by damaging the DNA of the hippocampal-nerve cells. In addition, Lipton et al. ${ }^{21}$ reported that under certain morbid conditions, such as shock or head injury, the neurotoxic effect of homocysteine overwhelms its normal neuroprotective effect because homocysteine acts as a partial antagonist for the glycine coagonist site of the NMDA receptor. Spiro et al. ${ }^{22}$ in their study on schizophrenia patients who had homocystinuria, suggested the possibility of the abnormality of methionine metabolism in some of the patients. They further reported that when methionine, a precursor of homocysteine, was administered to the schizophrenia patients, their symptoms were aggravated. ${ }^{22,23}$ The administration of betaine (a methyl donor) to the patients also aggravated their symptoms. ${ }^{24}$

Since the late 1990s, systematic studies have been performed on patients with schizophrenia due to homocysteine, and on normal control subjects. In a study conducted on schizophrenia patients, Regland et al. ${ }^{25}$ reported that a high homocysteine level was observed in $45 \%$ (nine of the 20 patients) of the patient group, asserting that the high homocysteine level was due to a genetic defect associated with methylation regardless of the patient's nutritive conditions, such as the level of folate or cobalamine, or psychotropic-drug administration. Unlike in the previous studies, however, Virgos et al. ${ }^{20}$ reported that in a comparative study of 210 Spanish schizophrenia patients and 218 Spanish normal control subjects, only $10 \%$ of the schizophrenia patients showed high serum homocysteine levels because of their folate-rich Mediterranean diet. There was no difference between the serum homocysteine levels of the two groups. This study by Virgos et al. ${ }^{20}$ came under fire, however, because most of the study subjects were male whose average age was 58. Levine et al. ${ }^{7}$ compared 193 schizophrenia patients and 762 normal control subjects based on sex and age. Consistent with the clinical trend in which the onset of schizophrenia occurs at a rather early age for men, and in which the degenerative course is common, the result of the comparison showed that the serum homocysteine level was significantly higher in the young patient group. Levine et al. ${ }^{7}$ postulated that the higher serum homocysteine levels in the young patient group were due to their high stress levels, which enabled toxic substances to easily pass through their serum brain barriers (BBBs).
In this study, the serum homocysteine level was significantly higher in the patient group than in the normal control group, regardless of age. A high serum homocysteine level corresponding to 90 percentile of the normal control group was observed in $33.7 \%$ of the schizophrenia patients, particularly in $51.5 \%$ of the male patients, similar to $45 \%$ in the study by Regland et al. ${ }^{25}$ Although consistent with the result of the study by Levine et al. ${ }^{7}$ the serum homocysteine level was also high in the males in this study, and no clinical characteristics (e.g., early onset and degenerative course of the schizophrenia) were observed. There have been many reports that the administration of folate to schizophrenia patients with MTHFR defects normalized their serum homocysteine levels. ${ }^{12,13,26}$ Mudd et al. ${ }^{27}$ reported that one of three schizophrenia patients who had an MTHFR defect showed improvement in his symptoms after taking folic acid. Freeman et al. ${ }^{12}$ also reported that the administration of folate to a mildly mentally retarded female teenager who had a high homocysteine level due to a disorder in her MTHFR activity improved her symptoms. Susser et al. $^{28}$ asserted that there are patients with schizophrenia who have a folate-sensitive homocysteine metabolism disorder, reporting that the serum homocysteine level was significantly higher in the patient group with low serum folate levels than in the normal control group with low serum folate levels. There was no difference, however, between the homocysteine levels of the patient group with normal serum folate levels and those of the normal control group.

In this study, most of the schizophrenia patients belonged to a group with low serum folate levels, whereas the normal control group belonged to a group with high or normal serum folate levels. For both groups with either low or high serum folate levels, the patient group showed higher serum homocysteine levels than the normal control group. Moreover, the coefficient of the inverse correlation between homocysteine and folate was higher in the patient group than in the normal control group. In particular, the schizophrenia patients who had low serum folate levels showed exceptionally high serum homocysteine levels compared with the normal control group.

The results of this study are similar to those of most of the previous studies, although Petronijević et al. ${ }^{1}$ reported that no significant correlation between the plasma homocysteine and folate levels in the patients was shown upon their admission into the hospital. In particular, consistent with the result of the study conducted by Susser et al. ${ }^{29}$ the homocysteine levels were higher in the patient group with low serum folate levels than in the normal control group with low serum folate levels. The result of this study, however, differed from that of Virgos et al. ${ }^{20}$ who reported that only $10 \%$ of the schizophrenia patients in their study showed high serum homocysteine levels, and that there was no difference between the serum ho- 
mocysteine levels of the patient and normal control groups. This difference is attributed to the folate-rich Mediterranean diet of the subjects in the study conducted by Virgos et al. ${ }^{20}$ Thus, considering the possibility that the subjects in this study had a low-folate diet because they were hospitalized in a mental hospital, where a folate-rich diet was unavailable, it was postulated that there could be many schizophrenia patients who have a folate-sensitive homocysteine metabolism disorder.

In this study, as the odd ratios of the risk of high serum homocysteine and vitamin $\mathrm{B}_{12}$ levels for schizophrenia were merely 1.07 and 1.003 , respectively, they cannot be used as decisive predictors of the onset of the disease. In contrast, for a high serum folate level, the odd ratio was 0.84 , indicating that it reduced the possibility of the incidence of schizophrenia, consistent with the result of Regland et al. ${ }^{28}$ who asserted that folate could help prevent the incidence of schizophrenia.

Taken together, for people who have a genetic homocysteine metabolism disorder and who have a low folate intake, a high serum homocysteine level is expected to occur, which may be consequently affected by the onset, symptoms, and course of schizophrenia. The major limitation of this study is that it did not make use of a more objective measurement tool to identify the clinical features of the schizophrenia patients. Subsequently, the clinical data had low reliability. In addition, due to the fact that the subject schizophrenia patients were in-patients in a mental hospital, they had a low-folate diet compared with the normal control subjects. Further studies are required to identify the clinical features of schizophrenia patients who have high and normal serum homocysteine levels, using more objective study tools, such as PANSS (positive-and-negative-syndrome scale), which was used in the study of Petronijević et al. ${ }^{1}$

Moreover, to determine the changes in the homocysteine level and psychopathology, follow-up studies must be conducted on schizophrenia patients who have high serum homocysteine levels due to a genetic MTHFR defect, and on those who have low serum folate levels, after the administration of a sufficient amount of folate.

\section{Acknowledgments}

This paper was supported by Konkuk University in 2008.

\section{REFERENCES}

1. Petronijević ND, Radonjić NV, Ivković MD, Marinković D, Piperski VD, Duricić BM, et al. Plasma homocysteine levels in young male patients in the exacerbation and remission phase of schizophrenia. Prog Neuropsychopharmacol Biol Psychiatry 2008;32:1921-1926.

2. Kale A, Naphade N, Sapkale S, Kamaraju M, Pillai A, Joshi S, et al. Reduced folic acid, vitamin B12 and docosahexaenoic acid and increased homocysteine and cortisol in never-medicated schizophrenia patients: Implications for altered one-carbon metabolism. Psychiatry Res 2010; 175:47-53.
3. Furie KL, Kelly PJ. Homocyst(e)ine and stroke. Semin Neurol 2006;26: 24-32.

4. Seshadri S, Beiser A, Selhub J, Jacques PF, Rosenberg IH, D’Agostino $\mathrm{RB}$, et al. Plasma homocysteine as a risk factor for dementia and Alzheimer's disease. N Engl J Med 2002;346:476-483.

5. Kim JM, Kim SW, Shin IS, Yang SJ, Park WY, Kim SJ, et al. Folate, vita$\min \mathrm{b}(12)$, and homocysteine as risk factors for cognitive decline in the elderly. Psychiatry Investig 2008;5:36-40.

6. O'Suilleabhain PE, Oberie R, Bartis C, Dewey RB Jr, Bottiglieri T, DiazArrastia R. Clinical course in Parkinson's disease with elevated homocysteine. Parkinsonism Relat Disord 2006;12:103-107.

7. Levine J, Stahl Z, Sela BA, Gavendo S, Ruderman V, Belmaker Rh. Elevated homocysteine levels in young male patients with schizophrenia. Am J Psychiatry 2002;159:1790-1792.

8. Durand P, Prost M, Loreau N, Lussier-Cacan S, Blache D. Impaired homocysteine metabolism and atherothrombotic disease. Lab Invest 2001; 81:645-672.

9. Kruman II, Culmsee C, Chan SL, Kruman Y, Guo Z, Penix L, et al. Homocysteine elicits a DNA damage response in neurons that promotes apoptosis and hypersensitivity to excitotoxicity. J Neurosci 2000;20: 6920-6926.

10. Lipton SA, Kim WK, Choi YB, Kumar S, D’Emilia DM, Rayadu PV, et al. Neurotoxicity associated with dual actions of homocysteine at the Nmethyl-D-aspartate receptor. Proc Natl Acad Sci U S A 1997;94:59235928.

11. Levine J, Stahl Z, Sela BA, Ruderman V, Shumaico O, Babushkin I, et al. Homocysteine-reducing strategies improve symptoms in chronic schizophrenic patients with hyperhomocysteinemia. Biol Psychiatry 2006; 60:265-269.

12. Freeman JM, Finkelstein JD, Mudd SH. Folate-responsive homocystinuria and "schizophrenia". A defect in methylation due to deficient 5, 10-methylenetetrahydrofolate reductase activity. N Engl J Med 1975;292: 491-496.

13. Regland B, Johansson BV, Gottfries CG. Homocysteinemia and schizophrenia as a case of methylation dificiency. J Neural Transm Gen Sect 1994;98:143-152.

14. Jacques PF, Bostom AG, Williams RR, Ellison RC, Eckfeldt JH, Rosenberg IH, et al. Relation between folate status, a common mutation in methylenetetrahydrofolate reductase, and plasma homocysteine concentrations. Circulation 1996;93:7-9.

15. Joober R, Benkelfat C, Lal S, Bloom D, Labelle A, Lalonde P, et al. Association between the methylenetetrahydrofolate reductase $677 \mathrm{C} \rightarrow \mathrm{T}$ missense mutation and schizophrenia. Mol Psychiatry 2000;5:323-326.

16. García-Miss Mdel R, Pérez-Mutul J, López-Canul B, Solís-Rodríguez F, Puga-Machado L, Oxté-Cabrera A, et al. Folate, homocysteine, interleukin-6, and tumor necrosis factor alfa levels, but not the methylenetetrahydrofolate reductase C677T polymorphism, are risk factors for schizophrenia. J Psychiatr Res 2010;44:441-446.

17. American Psychiatric Association. Diagnostic and Statistical Manual of Mental Disorders, Fourth Edition. Washington, DC: American Psychiatric Press; 1994.

18. Nygård O, Refsum H, Ueland PM, Vollset SE. Major lifestyle determinants of plasma total homocysteine distribution: the Hordaland Homocysteine Study. Am J Clin Nutr 1998;67:263-270.

19. Susser E, Brown AS, Klonowski E, Allen RH, Lindenbaum J. Schizophrenia and impaired homocysteine metabolism: a possible association. Biol Psychiatry 1998;44:141-143.

20. Virgos C, Martorell L, Simó JM, Valero J, Figuera L, Joven J, et al. Plasma homocysteine and the methylenetetrahydrofolate reductase C677T gene variant: lack of association with schizophrenia. Neuroreport 1999; 10:2035-2038

21. Lipton SA, Kim WK, Choi YB, Kumar S, D’Emilia DM, Rayadu PV, et al. Neurotoxicity associated with dual actions of homocysteine at the N-methyl-D-aspartate receptor. Proc Natl Acad Sci U S A 1997;94: 5923-5928. 
22. Spiro HR, Schimke RN, Welch JP. Schizophrenia in a patient with a defect in methionine metabolism. J Nerv Ment Dis 1965;141:285-290.

23. Cohen SM, Nichols A, Wyatt R, Pollin W. The administration of methionine to schizophrenic patients: a review of ten studies. Biol Psychiatry 1974;8:209-225.

24. Brune GG, Himwich HE. Effects of methionine loading on behavior of schizophrenic patients. J Nerv Ment Dis 1962;134:447-450.

25. Regland B, Johansson BV, Grenfeldt B, Hjelmgren LT, Medhus M. Homocysteinemia is a common feature of schizophrenia. J Neural Transm Gen Sect 1995;100:165-169.

26. Pasquier F, Lebert F, Petit H, Zittoun J, Marquet J. Metylenetetrahydro- folate reductase deficiency revealed by a neuropathy in a psychotic adult. J Neurol Neurosurg Psychiatry 1994;57:765-766.

27. Mudd SH, Freeman JM. N-5,10-methylenetetrahydrofolate reductase deficiency and schizophrenia: a working hypothesis. J Psychiatr Res 1974; 11:259-262.

28. Regland B, Germgård T, Gottfries CG, Grenfeldt B, Koch-Schmidt AC. Homozygous thermolabile metylenetetrahydrofolate reductase in schizophrenia-like psychosis. J Neural Transm 1997;104:931-941.

29. Susser E, Brown AS, Klonowski E, Allen RH, Lindenbaum J. Schizophrenia and impaired homocysteine metabolism: a possible association. Biol Psychiatry 1998;44:141-143. 